\title{
Social Work Education
}

\section{Perceived stress and sleep quality among master's students in social work}

\author{
Hyunji Lee, Mary E. Rauktis \& Rachel A. Fusco
}

To cite this article: Hyunji Lee, Mary E. Rauktis \& Rachel A. Fusco (2021): Perceived stress and sleep quality among master's students in social work, Social Work Education, DOI: 10.1080/02615479.2021.1910231

To link to this article: https://doi.org/10.1080/02615479.2021.1910231

\section{Published online: 05 Apr 2021.}

Submit your article to this journal $\square$

Q View related articles ¿

View Crossmark data 


\title{
Perceived stress and sleep quality among master's students in social work
}

\author{
Hyunji Lee ${ }^{a}$, Mary E. Rauktis ${ }^{a}$ and Rachel A. Fusco ${ }^{b}$ \\ aSchool of Social Work, University of Pittsburgh, Pittsburgh, PA, USA; bSchool of Social Work, University of \\ Georgia, Athens, GA, USA
}

\begin{abstract}
Poor sleep quality is prevalent in professional graduate school students due to academic- and work-related stress. In addition, it has been found that high levels of perceived stress, including lifetime traumatic stress, are significantly associated with poor sleep quality. This study surveyed 196 MSW students from a university in the United States. The study revealed that the majority of MSW students had poor sleep quality, which was significantly associated with higher levels of perceived stress, poorer sleep habits and environments, and a greater number of experiences of lifetime traumattagdtic events. Importantly, perceived stress and lifetime experiences of traumatic events became less strongly associated with sleep quality after adding sleep habits and environment as a control variable. Findings from the study can guide social work educators to consider incorporating sleep hygiene education into self-care practice programs and offer MSW students these interventions within the MSW curriculum.
\end{abstract}

\section{ARTICLE HISTORY}

Received 5 October 2020

Accepted 25 March 2021

\section{KEYWORDS}

Sleep quality; sleep habits and environment; perceived stress; lifetime experiences of traumatic events; MSW students

\section{Introduction}

Although previous studies have widely identified that poor sleep quality and high levels of perceived stress are prevalent in graduate students due to their academic- and workrelated stress (Brick et al., 2010; Menon et al., 2015), little is known about sleep quality and perceived stress among social work students, particularly those in Master of Social Work (MSW) programs. One recent study reported that social work students, especially those who were employed, had the issues of sleep deprivation, stress, and burnout due to imbalance between academic work, paid work, and life (Benner \& Curl, 2018). Since master's students enrolled in accredited MSW programs have to complete both academic course work and a field internship of at least 900 hours across two years, and may have employment or family responsibilities, it is reasonable to assume that MSW students may suffer from poor sleep quality and quantity due to balancing academic, home and work responsibilities. The available evidence suggests that sleep problems are associated with deficits in functioning across a wide range of indicators of psychological, interpersonal and somatic well-being (Roberts et al., 2009)

CONTACT Hyunji Lee hyl34@pitt.edu 2117 Cathedral of Learning, School of Social Work, University of Pittsburgh, 4200 Fifth Avenue, Pittsburgh, PA 15260, USA

(c) 2021 Informa UK Limited, trading as Taylor \& Francis Group 
and physical health and sleepiness among college students (Pilcher et al., 2007). Specifically, Pilcher et al. (1997) classified sleep into two aspects: (1) sleep quantity; (2) sleep quality. In the study, while sleep quantity was measured by total amount of time in bed and total amount of time asleep, sleep quality was evaluated by asking the participants to rate their subjective feelings of sleep and satisfaction with sleep.

In addition to academic- and work-related stress, some studies have indicated that having adverse childhood experiences (ACE) is prevalent in MSW students (Gilin \& Kauffman, 2015; Rompf \& Royse, 1994; Thomas, 2016). For example, Thomas (2016) reported that experiences of four or more ACEs were prevalent in MSW students, as compared to general populations, including university students. Specifically, the vast majority of general populations had at least one ACE (39\%-44\%), and only $12 \%-17 \%$ of them reported on four or more ACEs. In contrast, 30\%-40\% of MSW students have been identified to have four or more ACEs (Gilin \& Kauffman, 2015; Thomas, 2016). Gilin and Kauffman (2015) also noted that MSW students with ACEs were likely to have posttraumatic stress while engaging in class discussion or field work. More specifically, it was proposed that while engaging in class discussion or field work, the MSW students would hear about traumatic experiences from colleagues or clients and associate the traumatic experiences to their own personal trauma histories, which could possibly elevate posttraumatic stress symptoms. Importantly, previous studies have shown that social workers engaging in direct practice with survivors of traumatic events were likely to be exposed to secondary traumatic stress (Bride, 2007; Lee et al., 2018). For example, Lee et al. (2018) discovered that this secondary traumatic stress significantly mediated the effects of exposure to secondary traumatic events on poor physical health, including sleep disturbances, among clinical social workers.

Moreover, poor sleep quality has been identified as being significantly associated with sociodemographic status (Ertel et al., 2011; Jean-Louis et al., 2000; Ruiter et al., 2011) and poor sleep hygiene (Grandneret al., 2013). Sleep hygiene is defined as a set of habits and behavior that promote sleep quality (Hauri, 1991). In other words, inadequate sleep hygiene indicates poor sleep habits (e.g., irregular bedtimes) and environment (e.g., uncomfortable beds) that disrupt sleep quality, including sleep duration, awakening at night, and sleep onset latency (Stepanski \& Wyatt, 2003). Specifically, Ruiter et al. (2011) comprehensively reviewed prior work on disparity in sleep quality. The study found that underrepresented racial/ethnic groups (particularly African Americans) had fewer hours of sleep, as compared to Whites (Ruiter et al., 2011). Of the reviewed studies, African Americans were shown to have poorer sleep habits and environment, such as drinking alcohol, reading, or watching TV in bed, compared to their counterparts (Grandner et al., 2013). Another review study also proposed that the disparity in sleep duration might be attributed to low-income status (Ertel et al., 2011). Specifically, Whinnery et al. (2014) discovered that low-income adults had fewer hours of sleep than did high-income adults. Given the previous findings on the significant associations between poor sleep quality and multiple factors (e.g., perceived stress, sociodemographic status, poor sleep habits and environment), the current study used a sample of MSW students and explored these relationships among sleep quality, sleep habits and environments, perceived stress, lifetime experiences of traumatic events, and sociodemographic status. 


\section{Sleep problems in professional graduate school students}

It has been shown that professional graduate school students have poor sleep quality (Brick et al., 2010; Menon et al., 2015; Myers et al., 2012). Specifically, high prevalence rates of poor sleep quality were found among graduate students in medical (Brick et al., 2010), nursing (Menon et al., 2015), and psychology schools (Myers et al., 2012). For example, Myers et al. (2012) indicated that having poor sleep habits was significantly associated with higher levels of perceived stress among psychology graduate students. Given that graduate students in schools of social work are similar to psychology graduate students in that they have to complete both academic course work and field work, it is possible to assume that the MSW students may also be at high risk for poor sleep quality and sleep habits, as well as high levels of perceived stress. In addition, Pallos et al. (2007) also found that over a quarter of graduate students (25.6\%) from 12 university campuses in Japan had poor sleep quality and that poor sleep quality was significantly associated with perceived health status, smoking, and perceived satisfaction with living standards, respectively.

\section{Child protective service workers' exposure to secondary traumatic stress and sleep problems}

Using a qualitative thematic content analysis, Griffiths, Royse, and Walker (2018) examined associations between perceived stress and self-reported health outcomes, including sleep problems, among child protective service workers (CPS). While analyzing the qualitative mentions of work-related stress and unhealthy habits and behavior by the CPS workers, the study found that these workers reported higher levels of work-related stress, unhealthy habits and behavior (e.g., unhealthy eating habits, a lack of exercise, etc.), poor mental and physical health outcomes, as well as work-life imbalance. Importantly, this study indicated that almost $28.6 \%$ of CPS workers, who listed unhealthy habits and behavior, suffered from sleep deprivation. One worker recounted that she frequently experienced nightmares due to the concerns about safety of children who were involved in the child welfare system. Notably, these workers having unhealthy habits and behavior frequently rated their health status as poor and even showed a greater intention to leave work. Given that CPS workers having poor health habits or behavior are likely to leave the field (Griffiths et al., 2018) and that social work students are likely to work in the child welfare systems as direct service workers (Whitaker et al., 2004), it seems critical to train CPS workers and social work students on self-care practices that can help them better address their work-related stress and poor health habits.

\section{Self-care practice and sleep hygiene education for social work students and social workers}

It has been identified that professional self-care practices are effective for alleviating academic stress in social work students (O'Neill et al., 2019) and for reducing risk of professional burnout in child welfare workers (Salloum et al., 2015). However, these studies have shown mixed findings (Bonifas \& Napoli, 2014; Salloum et al., 2015). For example, Salloum et al. (2015) found that while self-care practices improved professional 
burnout, there was no effect on lowering risk of secondary traumatic stress. The mixed results suggest that there should be another approach or additional interventions that can help the MSW students address perceived stress and sleep problems.

In fact, it has been documented that sleep hygiene education has effects on improved sleep quality (Brown et al., 2006; Sato \& Ambo, 2018) as well as sleep habits and environment (Baroni et al., 2018; Smart, 2019). For example, a study of college students discovered that a 30-minute sleep hygiene education program (Sleep Treatment and Education Program) was effective for improving sleep quality and habits at a 6-month post-test (Brown et al., 2006). In addition, another study found that a 90-minute sleep hygiene education program was effective for improving sleep quality in a sample of college students who experienced a traumatic event-the Great East Japan Earthquake of 2011. Although one recent study of social work students evidenced the effects of sleep health education on gaining knowledge of sleep habits (Spadola et al., 2020), there is no prior study examining the effects of sleep hygiene education on sleep quality and perceived stress in MSW students. Therefore, more empirical studies should be conducted to examine the effects of sleep hygiene education on sleep quality and perceived stress in MSW students. More importantly, further research is needed to discuss how to incorporate sleep hygiene education into self-care programs within MSW curriculum.

In summary, previous studies have shown that professional graduate students are likely to have higher levels of perceived stress and poor sleep quality (Myers et al., 2012). Specifically, there is research evidence that having adverse childhood experiences was prevalent in MSW students (Thomas, 2016) and that MSW students with trauma histories had high levels of perceived stress (Gilin \& Kauffman, 2015). It has also been documented that clinical social workers, who serve populations with trauma histories, are likely to be exposed to secondary traumatic stress (Bride, 2007; Lee et al., 2018). Taken together, it is possible that MSW students who have more experiences of traumatic events are more prone to higher levels of perceived stress, which may in turn increase the risk for poor sleep quality and adverse health outcomes. Although it has been identified that support from teams, colleagues, and supervisors can help social workers to reduce workrelated stress (Bell et al., 2003; Newell \& Nelson-Gardell, 2014), it may not be easy for them to immediately alleviate work-related stress and traumatic stress. Therefore, it is critical to identify protective factors that can effectively and more easily mitigate the adverse impacts of perceived stress on sleep quality in MSW students. Indeed, the extant literature has demonstrated that having healthy sleep habits and environments can serve as a potential protective factor for sleep quality (Baroni et al., 2018; Brown et al., 2006; Sato \& Ambo, 2018; Smart, 2019). Thus, educating MSW students about healthy sleep habits and environments can be more effective in addressing their perceived stress and sleep problems since it can be much easier for them to improve sleep habits and environments than to address high levels of perceived stress or lifetime traumatic stress.

\section{Current study}

To date, there has been no study examining relationships among sleep quality, sleep habits and environments, perceived stress, and lifetime experiences of traumatic events in MSW students. Thus, the primary aim of the current study was to explore whether sleep quality would be significantly associated with sleep habits and environments, perceived 
stress, and lifetime experiences of traumatic events. Then, the study sought to investigate whether sleep quality would remain significantly related to perceived stress, even after including sleep habits and environments as a control variable.

The research questions are the following:

(1) Do MSW students have poor sleep habits and environments as well as poor sleep quality?

(2) Is sleep quality significantly associated with sleep habits and environment, perceived stress, lifetime experiences of traumatic events, and sociodemographic characteristics (e.g., age, race, sex, annual household income)?

(3) Is sleep quality significantly associated with perceived stress, after controlling for lifetime experiences of traumatic events and sociodemographic characteristics?

(4) Does sleep quality remain significantly related to perceived stress, even after adding sleep habits and environment as a control variable?

\section{Method}

\section{Participants}

A convenience sampling method was employed to recruit the study participants. A researcher provided the study participants with information about data confidentiality and the study's potential benefits and harm. In addition, the students were informed that they had rights to withdraw from the research at any time if they decided to terminate their participation. The study was approved by the university's Institutional Review Board. Two hundred and two MSW students enrolled in 2019 at a US University participated in online or paper surveys. The study participants were asked to complete the anonymous online survey using a secure web-based survey tool, Qualtrics. A paper-based survey questionnaire was provided if the study participants preferred paper surveys. Six students who omitted to complete the values on a key study variable-sleep quality-were excluded, resulting in a final sample of 196 students in the current study. Based on the medium effect size of .15 (Cohen, 1988), at least 189 participants were needed as an analytic sample to identify significant relationships between sleep quality, sleep habits, perceived stress, and lifetime experiences of traumatic events.

\section{Measures}

\section{Demographic information}

A demographic questionnaire was developed by the researcher. Items included age, sex, marital status, the presence of a child, education level, race, annual household income, year of MSW program, previous employment status, as well as current employment status. The employment variables were measured by asking months of work experience, workplace (e.g., human service organizations/non-human service organizations), and employment status (e.g., full-time/part-time jobs). Both previous and current workplaces and employment status were dichotomous variables. Specifically, part-time jobs were defined as working between 1 and 29 hours per week, and full-time jobs were considered as working 30 or more hours per week. 


\section{Pittsburgh sleep quality index}

The Pittsburgh Sleep Quality Index (PSQI; Buysse et al., 1989) is a 19-item self-report measure, which evaluates seven domains of sleep-sleep quality, sleep onset latency, sleep duration, habitual sleep efficiency, sleep disturbances, use of sleep medication, and daytime dysfunction-over the past month. Sleep onset latency refers to the duration of time that it takes to fall asleep. Daytime dysfunction is measured by assessing problems with staying awake while driving, eating meals, or engaging in social activity because of sleepiness. The score on each domain was summed to calculate a total PSQI score. Each item was rated on a three-point scale, and the total PSQI scores ranged from 0 to 21, with higher scores indicating poorer sleep quality. According to the PSQI, the total PSQI score of less than 5 indicated good quality of sleep, whereas the total PSQI score of 5 or above 5 reflected poor quality of sleep. The PSQI demonstrated high test-retest reliability in a study of 80 patients with insomnia ( $r=.87$; Backhaus et al., 2002). The PSQI also indicated moderate convergent validity with the Insomnia Severity Index $(r=.63$; Bastien, 2001) and good divergent validity with measures of daytime sleepiness ( $r=.18$; Dietch et al., 2016). Cronbach's alpha for the PSQI was .83 (Buysse et al., 1989).

\section{Sleep hygiene index}

The Sleep Hygiene Index (SHI; Mastin et al., 2006) is a 13-item self-report measure, which assesses sleep habits and sleep environment. The study participants were asked to respond to a series of questions about their sleep habits and sleep environment, including items like 'I do something that may wake me up before bedtime', 'I go to bed feeling stressed, angry, upset, or nervous', and 'I sleep in an uncomfortable bed.' Each item was rated on a five-point scale ranging from 0 (never) to 4 (always). A total score ranged from 0 to 52, with higher scores reflecting poorer sleep habits and sleep environment. The SHI was normed on 632 undergraduate students and demonstrated good test-retest reliability $(r=.71)$ and validity with the PSQI ( $r=$. 48; Mastin et al., 2006). Cronbach's alpha for the SHI was .74 (Myers et al., 2012).

\section{Perceived stress scale}

The Perceived Stress Scale (PSS-14; Cohen et al., 1983), a 14-item self-report questionnaire, was used to measure perceived stress. The PSS-14 was normed on 446 college students. The items were rated on a five-point scale ranging from 0 (never) to 4 (very often), and total scores ranged from 0 to 56, with higher scores indicating severe perceived stress. The respondents were asked to answer a series of questions, including items like 'How often have you been upset because of something that happened unexpectedly?' and 'In the last month, how often have you found that you could not cope with all the things that you had to do?' The PSS-14 had adequate reliability $(r=.84)$, test-retest reliability $(r=.85)$, and divergent validity with the measures of depressive symptoms (Myers et al., 2012). Cronbach's alpha for the PSS-14 was .85 (Cohen et al., 1983).

\section{Brief trauma questionnaire}

The Brief Trauma Questionnaire (BTQ; Schnurr et al., 1999) is a 10-item self-administered questionnaire that measures lifetime histories of traumatic events, including motor vehicle 
accidents, natural disasters, physical abuse, sexual abuse. The respondents were asked to answer either 'Yes' or 'No' to each traumatic event. Kappa coefficients for the BTQ ranged from 0.74 to 1.00 , demonstrating good reliability and good validity (Schnurr et al., 2002).

\section{Data analysis}

This cross-sectional study used data collected from a survey conducted between March and April 2019. A series of univariate analyses was conducted to identify demographic characteristics of the study sample and descriptive statistics of the key study variables. In addition, bivariate analyses were performed to examine associations between the study variables. Moreover, as a primary analysis, hierarchical regression analyses were executed to identify whether sleep quality would be significantly accounted for by perceived stress, sleep habits and environment, lifetime experiences of traumatic events, and sociodemographic characteristics. Particularly, the final multiple regression model was performed to examine whether sleep quality would remain significantly related to perceived stress, after adding sleep habits and environment as a control variable.

\section{Results}

\section{Descriptive statistics}

\section{Sociodemographic characteristics}

Table 1 presents descriptive statistics of the key study variables and the sample characteristics. Of the total sample, 166 participants (85.13\%) were female, and 27 participants $(13.85 \%)$ were male. Two participants $(1.03 \%)$ indicated that they did not have a binary sex, and one participant did not respond to the question. The mean age of participants was $28(M=28.02 ; S D=6.33)$ ranging from 22 to 50 years. The majority of participants were Whites (75.4\%), followed by African Americans (12.3\%), Asians (4.6\%), multiracial $(5.1 \%)$, and other racial/ethnic groups $(2.6 \%)$. The vast majority of participants (76\%) had never been married; $22.4 \%$ of participants were married; and $1.6 \%$ were divorced or separated. Approximately $15 \%$ had a child, and $85 \%$ did not. Of the total sample, 137 students (70\%) were in the first year of the MSW program, 53 students $(27 \%)$ were in the second year of the MSW program, and only 6 students (3\%) were in the MSW program for more than two years. The vast majority of participants were full-time MSW students (74\%), followed by part-time MSW students (13\%) and advanced-standing MSW students (13\%). Advanced-standing MSW students, who hold a Bachelor of Social Work from a program accredited by the Council on Social Work Education, earn a master's degree in social work within a single calendar year (Council on Social Work Education [CSWE], n.d.).

\section{Sleep quality and sleep habits}

On average, the study reported that the study participants had 6.59 hours of sleep $(S D=1.06)$ a day, which is less than the recommended hours of sleep (between 7 and 9 hours per day) required for adults aged between 18 and 25 years (Centers for Disease Control and Prevention [CDC], 2017). In addition, the study participants were found to sleep between 3 and 13 hours per day. Moreover, on average, it took over a half of hour 
Table 1. Descriptive statistics of the study sample $(\mathrm{N}=196)$.

\begin{tabular}{|c|c|c|c|c|c|c|}
\hline Variable & $n$ & $\%$ & M & $S D$ & Min & $\operatorname{Max}$ \\
\hline Sleep quality & - & - & 7.58 & 3.40 & 1 & 19 \\
\hline Sleep habits and environment & - & - & 22.4 & 6.49 & 4 & 37 \\
\hline Perceived stress & - & - & 27.4 & 7.17 & 6 & 50 \\
\hline Lifetime experiences of traumatic events & - & - & 1.66 & 1.41 & 0 & 8 \\
\hline Age & - & - & 28 & 6.33 & 22 & 50 \\
\hline \multicolumn{7}{|l|}{$\operatorname{Sex}(n=195)$} \\
\hline Female & 166 & 85.1 & - & - & - & - \\
\hline Male & 27 & 13.9 & - & - & - & - \\
\hline Non-binary sex & 2 & 1.03 & - & - & - & - \\
\hline \multicolumn{7}{|l|}{ Race $(n=195)$} \\
\hline White & 147 & 75.4 & - & - & - & - \\
\hline African American & 24 & 12.3 & - & - & - & - \\
\hline Asian & 9 & 4.62 & - & - & - & - \\
\hline Multiracial & 10 & 5.13 & - & - & - & - \\
\hline Other & 5 & 2.56 & - & - & - & - \\
\hline \multicolumn{7}{|l|}{ Year in MSW program } \\
\hline 1st year in MSW program & 137 & 69.9 & - & - & - & - \\
\hline 2nd year in MSW program & 53 & 27 & - & - & - & - \\
\hline More than two years in MSW program & 6 & 3.06 & - & - & - & - \\
\hline \multicolumn{7}{|l|}{ MSW program } \\
\hline Full-time MSW program & 145 & 74 & - & - & - & - \\
\hline Part-time MSW program & 26 & 13.3 & - & - & - & - \\
\hline Advanced standing MSW program & 25 & 12.8 & - & - & - & - \\
\hline \multicolumn{7}{|l|}{ Household income $(n=169)$} \\
\hline Under $\$ 10,000$ & 44 & 26 & - & - & - & - \\
\hline$\$ 10,000$ to just under $\$ 20,000$ & 23 & 13.6 & - & - & - & - \\
\hline$\$ 20,000$ to just under $\$ 30,000$ & 19 & 11.2 & - & - & - & - \\
\hline$\$ 30,000$ to just under $\$ 40,000$ & 14 & 8.28 & - & - & - & - \\
\hline$\$ 40,000$ to just under $\$ 50,000$ & 16 & 9.47 & - & - & - & - \\
\hline$\$ 50,000$ and higher & 53 & 31.4 & - & - & - & - \\
\hline \multicolumn{7}{|l|}{ Marital status $(n=192)$} \\
\hline Married & 43 & 22.4 & - & - & - & - \\
\hline Never married & 146 & 76.04 & - & - & - & - \\
\hline Divorced/separated & 3 & 1.56 & - & - & - & - \\
\hline \multicolumn{7}{|l|}{ Children $(n=195)$} \\
\hline No & 166 & 85.13 & - & - & - & - \\
\hline Yes & 29 & 14.87 & - & - & - & - \\
\hline \multicolumn{7}{|l|}{ Previous employment $(n=176)$} \\
\hline \multicolumn{7}{|l|}{ Previously employed } \\
\hline No & 5 & 2.84 & - & - & - & - \\
\hline Yes & 171 & 97.16 & - & - & - & - \\
\hline \multicolumn{7}{|l|}{ Previous workplace $(n=171)$} \\
\hline Human service organization & 116 & 67.84 & - & - & - & - \\
\hline Non-human service organization & 55 & 32.16 & - & - & - & - \\
\hline \multicolumn{7}{|l|}{ Employment status $(n=171)$} \\
\hline Part-time & 52 & 30.41 & - & - & - & - \\
\hline Full-time & 119 & 69.59 & - & - & - & - \\
\hline \multicolumn{7}{|l|}{ Current employment $(n=194)$} \\
\hline \multicolumn{7}{|l|}{ Currently employed } \\
\hline No & 67 & 34.54 & - & - & - & - \\
\hline Yes & 127 & 65.46 & - & - & - & - \\
\hline \multicolumn{7}{|l|}{ Current workplace $(n=127)$} \\
\hline Human service organization & 81 & 63.78 & - & - & - & - \\
\hline Non-human service organization & 46 & 36.22 & - & - & - & - \\
\hline \multicolumn{7}{|l|}{ Employment status $(n=127)$} \\
\hline Part-time & 90 & 70.87 & - & - & - & - \\
\hline Full-time & 37 & 29.13 & - & - & - & - \\
\hline
\end{tabular}

$(M=31.4 ; S D=23.3)$ for participants to fall asleep. Specifically, a wide range of sleep onset latency was found (ranges between 5 minutes and 130 minutes), indicating that some participants might suffer from insomnia. The average PSQI score was 7.58 
$(S D=3.4)$ ranging between 1 and 19. Based on the PSQI's criteria for sleep quality, the majority of this MSW student sample (70.4\%) had poor sleep quality, and only a few students (29.6\%) were identified as having good quality of sleep (scoring less than 5 ). The PSQI measure also asked the respondents to rate their perceived sleep quality during the past month. Over half of them (55.6\%) perceived their sleep quality as fairly good, while the second largest sample (33.7\%) rated it as fairly bad. The average score of sleep habits and environment was $22.4(S D=6.49)$ ranging from 4 to 37 .

\section{Perceived stress}

The average score of perceived stress was $27.43(S D=7.17)$, and the perceived stress scores were normally distributed (skewness $=.21$; kurtosis $=3.34$ ). Specifically, $48 \%$ of MSW students had higher levels of perceived stress than the average score of perceived stress, indicating that almost half of this sample felt distressed and perceived that they were not able to cope with the unexpected things in the past month.

\section{Lifetime experiences of traumatic events}

Regarding the lifetime experiences of traumatic events, the mean number of experiences of lifetime traumatic events that occurred to the study participants was approximately $1.66(S D=1.41)$. This indicates that the MSW students had at least one experience of traumatic events throughout their lifetimes on average. The majority of MSW students (30.53\%) were found to have one experience of lifetime traumatic events; $24.21 \%$ had two experiences; $14.74 \%$ had three experiences; only $8.95 \%$ reported that they experienced four or more traumatic events throughout their lifetimes.

\section{Bivariate analyses}

Table 2 shows the bivariate relationships between key study variables. Sleep quality was significantly associated with perceived stress, sleep habits and environment, and the number of lifetime experiences of traumatic events, respectively. Specifically, poor sleep quality was positively associated with poor sleep habits and environment $(r=.44$, $p=.000)$, higher levels of perceived stress $(r=.39, p=.000)$, and a greater number of lifetime experiences of traumatic events $(r=.31, p=.000)$. Importantly, poor sleep habits and environment were significantly associated with higher levels of perceived stress $(r=.54, p=.000)$ and a greater number of lifetime experiences of traumatic events $(r=.23, p=.001)$. Interestingly, while sleep quality was not significantly associated with age $(r=0.07, p=0.34)$, sleep habits and environment had a negative relationship with age $(r=-.23, p=.001)$, suggesting that older students have more resources or capabilities to

Table 2. Correlation matrix of key study variables $(\mathrm{N}=196)$.

\begin{tabular}{|c|c|c|c|c|c|c|}
\hline Variable & 1 & 2 & 3 & 4 & 5 & 6 \\
\hline 1. Sleep quality & - & & & & & \\
\hline 2. Sleep habits and environment & $.44^{* * *}$ & - & & & & \\
\hline 3. Perceived stress & $.39 * * *$ & $.54 * * *$ & - & & & \\
\hline 4. Lifetime experiences of traumatic events & $.31^{* * *}$ & $.23 * *$ & $.27^{* * *}$ & - & & \\
\hline 5. Age & .07 & $-.23^{* *}$ & $-.20^{* *}$ & .11 & - & \\
\hline 6. Annual household income & -.09 & $-.31^{* * *}$ & $-.35^{* * *}$ & -.08 & $.40^{* * *}$ & 一 \\
\hline
\end{tabular}


improve sleep habits and environment. In terms of annual household income, lower annual household income was significantly associated with poorer sleep habits and environment $(r=-.31, p=.000)$ and higher levels of perceived stress $(r=-.35$, $p=.000$ ), respectively. This finding suggests that those having higher levels of household income might have better sleep habits and environment and lower levels of perceived stress.

\section{Multiple regression analyses}

A series of t-tests and analyses of variance (ANOVA) were conducted to identify and include significant sociodemographic variables in the multiple regression models as control variables. Considering the distribution of sleep quality by age, the age variable was dichotomized to better capture the variability in sleep quality. There are two age subgroups: (1) the younger group (aged 30 or below 30 years); (2) the older group (aged over 30 years). Race/ethnicity, sex, and annual household income were also included as control variables in the multiple regression models since the prior research has documented significant differences in sleep quality according to race/ethnicity (Fuller-Rowell et al., 2017), sex (Arber et al., 2009; Duncan et al., 2018), and low household income (Sivertsen et al., 2017).

Tolerance value of each predictor indicated that there was no sign of multicollinearity. Table 3 shows the results of the multiple regression analyses. In the first multiple regression model, it was found that control variables-the number of lifetime experiences of traumatic events and sociodemographic status (i.e., age, sex, race, annual household income)-significantly accounted for sleep quality, $F(9,148)=312, p=.002, R^{2}=0.16$. Specifically, a greater number of lifetime experiences of traumatic events was associated with poorer sleep quality $(\beta=.29, t=3.64, p=.000)$. Notably, of the sociodemographic

Table 3. Multiple regression models predicting sleep quality $(\mathrm{N}=196)$.

\begin{tabular}{|c|c|c|c|c|c|c|c|c|c|}
\hline \multirow[b]{2}{*}{ Variable } & \multicolumn{3}{|c|}{ Model 1} & \multicolumn{3}{|c|}{ Model 2} & \multicolumn{3}{|c|}{ Model 3} \\
\hline & B & SE & $\beta$ & $B$ & SE & $\beta$ & $B$ & SE & $\beta$ \\
\hline \multicolumn{10}{|l|}{ Sex (ref: Female) } \\
\hline Male & -.79 & .80 & -.08 & -.38 & .78 & -.04 & -.51 & .75 & -.05 \\
\hline Non-binary & -1.10 & 2.39 & -.04 & -1.67 & 2.25 & -.06 & -2.99 & 2.2 & -.10 \\
\hline \multicolumn{10}{|l|}{ Race (ref: Whites) } \\
\hline African American & .49 & .83 & .05 & .39 & .78 & .04 & .65 & .75 & .06 \\
\hline Asian & -.52 & 1.37 & -.03 & -.06 & 1.29 & -.00 & -.44 & 1.25 & -.03 \\
\hline Multiracial & 1.91 & 1.15 & .13 & 1.32 & 1.09 & .09 & 1.45 & 1.05 & .10 \\
\hline Other & .78 & 3.27 & .02 & 1.18 & 3.07 & .03 & 1.41 & 2.96 & .03 \\
\hline Annual household income & -.21 & .14 & -.13 & -.011 & .14 & -.01 & .05 & .13 & .03 \\
\hline \multicolumn{10}{|l|}{ Age (ref: Aged over 30 years) } \\
\hline Aged 30 or under 30 years & -1.71 & .66 & $-.21^{*}$ & -1.76 & .62 & $-.22^{* *}$ & -1.87 & .60 & $-.23^{* *}$ \\
\hline $\begin{array}{l}\text { Lifetime experiences of traumatic } \\
\text { events }\end{array}$ & .67 & .18 & $.29^{* * *}$ & .45 & .18 & $.19^{*}$ & .39 & .17 & $.16^{*}$ \\
\hline Perceived stress & & & & .17 & .04 & $.38^{* * *}$ & .12 & .04 & $.23^{*}$ \\
\hline Sleep habits and environment & & & & & & & .16 & .05 & $.30^{* * *}$ \\
\hline Intercept & $8.56^{* * *}$ & .96 & & $3.44^{*}$ & 1.42 & & 1.87 & 1.44 & \\
\hline $\mathrm{N}$ & & & 158 & & & 157 & & & 157 \\
\hline$F$ & & & 3.12 & & & 5.41 & & & 6.35 \\
\hline$R^{2}$ & & & .16 & & & .27 & & & .33 \\
\hline$R_{\text {adjusted }}^{2}$ & & & .11 & & & .22 & & & .27 \\
\hline$\Delta R^{2}$ & & & & & & $.11^{* * *}$ & & & $.06^{* *}$ \\
\hline
\end{tabular}

${ }^{*} p<0.05,{ }^{* *} p<0.01,{ }^{* * *} p<0.001$. 
variables, only age had a significant relationship with sleep quality $(\beta=-.21, t=-2.57$, $p=.011)$.

In the second regression model, the perceived stress variable was added to examine whether perceived stress would be significantly associated with sleep quality after controlling for the lifetime experiences of traumatic events and sociodemographic status. The second model was significant, $F(10,146)=5.41, p=.000, R^{2}=0.27$. In this model, the perceived stress $(\beta=.38, t=4.68, p=.000)$, the number of lifetime experiences of traumatic events $(\beta=.19, t=2.49, p=.014)$, and age $(\beta=-.22, t=-2.82, p=.005)$ variables were all significantly related to sleep quality. Importantly, the perceived stress variable had the strongest relationship with sleep quality. In other words, higher levels of perceived stress were associated with poorer sleep quality.

Lastly, the sleep habits and environment variable was added to the final regression model in order to identify whether perceived stress would remain significantly related to sleep quality, even after including the sleep habits and environment variable as a control variable. The final regression model was significant, $F(11,145)=6.35, p=.000, R^{2}=0.33$. The results of the final regression model revealed that sleep quality was significantly associated with sleep habits and environment $(\beta=.30, t=3.44, p=.001)$, perceived stress $(\beta=.23, t=2.55, p=.012)$, the lifetime experiences of traumatic events $(\beta=.16, t=2.21$, $p=.029)$, and age $(\beta=-.23, t=-3.11, p=.002)$. Poor sleep quality remained significantly associated with higher levels of perceived stress, even after adding the sleep habits and environment variable as a control variable. More importantly, it should be noted that the magnitude of the relationship between perceived stress and sleep quality was attenuated, indicating that perceived stress became less strongly associated with sleep quality, after controlling for sleep habits and environment. The final model also showed that older MSW students had poorer sleep quality, as compared to younger MSW students, after controlling for sleep habits and environment. This finding suggests that the older MSW students may need interventions targeting poor sleep quality.

\section{Discussion}

Consistent with the previous findings on the high prevalence of poor sleep quality in professional graduate students (Brick et al., 2010; Menon et al., 2015), the majority of MSW students had poor sleep quality and fewer hours of sleep than the recommended hours of sleep for adults (CDC, 2017). Almost half of MSW students had higher levels of perceived stress than the average level of perceived stress of the total sample. Poor sleep quality was significantly associated with higher levels of perceived stress, poorer sleep habits and environment, and a greater number of experiences of lifetime traumatic events. Importantly, multiple regression models revealed that although high levels of perceived stress remained significantly related to poor sleep quality, perceived stress became less strongly associated with sleep quality, after including sleep habits and environment as a control variable. This finding adds additional supports to the previous findings that healthy sleep habits and environment can possibly serve as a buffer against poor sleep quality (Brown et al., 2006; Sato \& Ambo, 2018). It is also worth noting that while the current study discovered a significant relationship between sleep quality and age, sleep quality was not associated with other sociodemographic variables (i.e., sex, race, and annual household income), a finding which was inconsistent with the previous 
studies (Arber et al., 2009; Duncan et al., 2018; Fuller-Rowell et al., 2017; Sivertsen et al., 2017).

Why should social work educators be concerned about the quality of student sleep as this is an area of personal habits and life choices, not curricula? One reason is the close relationship between sleep and emotional functioning (Watling et al., 2017). Sleep deprivation, for instance, was found to result in heighted activity in the amygdala and reduced connectivity between the amygdala and prefrontal cortex, suggesting elevated emotional responses without the benefit of contextualization of higher brain functioning (Yoo et al., 2007). Moreover, Zhang et al. (2019) found compromised emotional functioning after sleep loss, highlighting the importance of sleep to emotional regulation.

Social work students are also practicing how to be present with clients in difficult situations or with painful or traumatic histories, and this requires emotional regulation or emotional intelligence on the part of the social work students (Ingram, 2013). It has been widely identified that social work students are likely to face challenges with managing emotional reactions while working with these clients (Collins et al., 2010; Grant et al., 2014). If they are experiencing poor sleep then a student may struggle with managing emotional expression or they may control their flight/fright emotions externally but internalize the stress response. Those who do not release stress and internalize the stress response could have high levels of untreated emotional distress, which may contribute to burnout (Conrad \& Kellar-Guenther, 2006) and poor health outcomes (Kim et al., 2011). Some studies have emphasized the importance of supports from colleagues (Ingram, 2013) and having discussions with supervisors (Bell et al., 2003; Grant et al., 2014), which can play a significant role in coping with stress and regulating emotions among social work students. Although reflective and supportive supervision is helpful in dealing with strong emotional responses to work situations (Rauktis \& Thomas, 2013), educating students about the biology of stress and sleep, and how to attend to their own sleeping habits and environment fits within social work education and the 'person in the environment' framework and 'stress-resilience' theory used in social work practice with clients. Some social work departments have started to help students to manage the stress of social work education, and program evaluations have found positive results (Bonifas \& Napoli, 2014; Botta et al., 2015; Dziegielewski et al., 2004). For example, one study suggests that mindfulness practices focusing on selfcompassion is a fruitful area for strengthening resilience (Kemper et al., 2015). In addition, the use of self-care journal assignment or reflective writing has been identified as effective for reducing stress (Grant et al., 2014; Moore et al., 2011) and increasing engagement in self-care practices (Shannon et al., 2014). Of the few empirical studies of self-care programs in social work education, however, these studies have primarily focused on mindfulness practice and tested the effectiveness of integrating mindfulnessbased interventions into social work curriculum (Griffiths et al., 2019). Since there is a variety of forms of self-care, more empirical research needs to develop and implement effective self-care programs that could be integrated into the social work curriculum. Specifically, few social work self-care programs address healthy sleep habits and environment, even though this can be a modifiable behavior. Therefore, further research is needed to discuss how to combine sleep hygiene education with other self-care programs 
in social work education and to examine the effects of these interventions on sleep quality and perceived stress in MSW students.

\section{Limitations}

The results of the study should be interpreted with caution. First, this study used crosssectional data and has no data about perceived stress, sleep quality, and sleep habits and environment in the MSW students before they entered the MSW programs; as such, time ordering between the observed relationships cannot be established. Thus, more longitudinal studies should collect data at multiple time points, allowing for investigating the role of healthy sleep habits and environment in mitigating adverse effects of perceived stress on sleep quality. Second, because this study surveyed the MSW students around midterm, these students might have been particularly prone to poor sleep quality and higher levels of perceived stress, threatening the reliability of the results from the study. Third, over $70 \%$ of this sample were first-year MSW students, and some of them reported that they had not yet been assigned to a field placement. Thus, the study results might differ if more second-year MSW students, who had already engaged in field work, were included in the study. Fourth, with the exception of age, other sociodemographic variables were not significantly associated with sleep quality. This might be due to the fact that the majority of MSW students were White and female. Therefore, future studies need to recruit a larger population of MSW students across the United States and other countries to address sampling bias. Lastly, the study used a self-reported measure, i.e., PSQI, to assess sleep quality, which is susceptible to measurement error; thus, further research is needed to employ both objective and subjective measures to evaluate sleep quality more accurately.

\section{Implications}

Despite the limitations, the results of the study have important implications for social work education. The findings on the high prevalence of poor sleep quality in MSW students highlights the importance of education on sleep quality as well as sleep habits and environment for social work students. The findings can also guide social work educators to consider including within the MSW curriculum a course on self-care which would include information about healthy sleep habits and environment combined with other known stress-reducing interventions, such as progressive relaxation, meditation, mindfulness-based activities or guided imagery. This kind of intervention can even be evaluated and tracked by the student using single case design, embedding research into a course on self-care. Finally, this suggestion is congruent with social work's theoretical frameworks of stress and resilience and helping clients within their environments. We hope that others will consider ways to include educational and support interventions focusing on sleep within their curricular framework.

\section{Disclosure statement}

No potential conflict of interest was reported by the author(s). 


\section{Notes on contributors}

Hyunji Lee, MSW, is a doctoral candidate in the School of Social Work at the University of Pittsburgh. Her research interests include healthy biopsychosocial development of children and youth and developmental trajectories of children and youth with adverse childhood experiences.

Mary Elizabeth Rauktis, PhD, is research faculty in the School of Social Work at the University of Pittsburgh. Her research and scholarship focus on interventions for child welfare involved youth in residential care, public child welfare workforce adoption of interventions, and the experiences of multiracial families in child welfare services.

Rachel A. Fusco, PhD, MSW, is an associate Professor and Georgia Athletic Association Professor in Health and Well-Being in the School of Social Work at the University of Georgia. Her research, scholarship, and teaching focus on mental health and well-being of young children and their mothers, especially in families experiencing child maltreatment and/or intimate partner violence.

\section{References}

Arber, S., Bote, M., \& Meadows, R. (2009). Gender and socio-economic patterning of self-reported sleep problems in Britain. Social Science \& Medicine, 68(2), 281-289. https://doi.org/10.1016/j. socscimed.2008.10.016

Backhaus, J., Junghanns, K., Broocks, A., Riemann, D., \& Hohagen, F. (2002). Test-retest reliability and validity of the Pittsburgh Sleep Quality Index in primary insomnia. Journal of Psychosomatic Research, 53(3), 737-740. https://doi.org/10.1016/S0022-3999(02)00330-6

Baroni, A., Bruzzese, J.-M., Di Bartolo, C. A., Ciarleglio, A., \& Shatkin, J. P. (2018). Impact of a sleep course on sleep, mood and anxiety symptoms in college students: A pilot study. Journal of American College Health, 66(1), 41-50. https://doi.org/10.1080/07448481.2017. 1369091

Bastien, C. (2001). Validation of the Insomnia Severity Index as an outcome measure for insomnia research. Sleep Medicine, 2(4), 297-307. https://doi.org/10.1016/S1389-9457(00)00065-4

Bell, H., Kulkarni, S., \& Dalton, L. (2003). Organizational prevention of vicarious trauma. Families in Society: The Journal of Contemporary Social Services, 84(4), 463-470. https://doi.org/10.1606/ 1044-3894.131

Benner, K., \& Curl, A. L. (2018). Exhausted, stressed, and disengaged: Does employment create burnout for social work students? Journal of Social Work Education, 54(2), 300-309. https://doi. org/10.1080/10437797.2017.1341858

Bonifas, R. P., \& Napoli, M. (2014). Mindfully increasing quality of life: A promising curriculum for MSW students. Social Work Education, 33(4), 469-484. https://doi.org/10.1080/02615479. 2013.838215

Botta, A. A., Cadet, T. J., \& Maramaldi, P. (2015). Reflections on a quantitative, group-based mindfulness study with social work students. Social Work with Groups, 38(2), 93-105. https:// doi.org/10.1080/01609513.2014.975885

Brick, C. A., Seely, D. L., \& Palermo, T. M. (2010). Association between sleep hygiene and sleep quality in medical students. Behavioral Sleep Medicine, 8(2), 113-121. https://doi.org/10.1080/ 15402001003622925

Bride, B. E. (2007). Prevalence of secondary traumatic stress among social workers. Social Work, 52 (1), 63-70. https://doi.org/10.1093/sw/52.1.63

Brown, F. C., Buboltz Jr., W. C., Jr, \& Soper, B. (2006). Development and evaluation of the sleep treatment and education program for students (STEPS). Journal of American College Health, 54 (4), 231-237. https://doi.org/10.3200/JACH.54.4.231-237

Buysse, D. J., Reynolds, C. F., Monk, T. H., Berman, S. R., \& Kupfer, D. J. (1989). The Pittsburgh sleep quality index: A new instrument for psychiatric practice and research. Psychiatry Research, 28(2), 193-213. https://doi.org/10.1016/0165-1781(89)90047-4 
Centers for Disease Control and Prevention (2017). Sleep and sleep disorders. U.S. Department of Health and Human Services. https://www.cdc.gov/sleep/data_statistics.html

Cohen, J. (1988). Statistical power analysis for the behavioral sciences. L. Erlbaum Associates.

Cohen, S., Kamarck, T., \& Mermelstein, R. (1983). A global measure of perceived stress. Journal of Health and Social Behavior, 24(4), 385. https://doi.org/10.2307/2136404

Collins, S., Coffey, M., \& Morris, L. (2010). Social work students: Stress, support and well-being. British Journal of Social Work, 40(3), 963-982. https://doi.org/10.1093/bjsw/bcn148

Conrad, D., \& Kellar-Guenther, Y. (2006). Compassion fatigue, burnout, and compassion satisfaction among Colorado child protection workers. Child Abuse \& Neglect, 30(10), 1071-1080. https://doi.org/10.1016/j.chiabu.2006.03.009

Council on Social Work Education. (n.d.). Social work education at a glance. https://www.cswe. org/Students/Prepare-for-Your-Career/Social-Work-At-A-Glance

Dietch, J. R., Taylor, D. J., Sethi, K., Kelly, K., Bramoweth, A. D., \& Roane, B. M. (2016). Psychometric evaluation of the PSQI in U.S. college students. Journal of Clinical Sleep Medicine, 12(8), 1121-1129. https://doi.org/10.5664/jcsm.6050

Duncan, D. T., Kanchi, R., Tantay, L., Hernandez, M., Letamendi, C., Chernov, C., \& Thorpe, L. (2018). Disparities in sleep problems by sexual orientation among New York city adults: An analysis of the New York city health and nutrition examination survey, 2013-2014. Journal of Urban Health, 95(6), 781-786. https://doi.org/10.1007/s11524-018-0268-0

Dziegielewski, S. F., Turnage, B., \& Roest-Marti, S. (2004). Addressing stress with social work students: A controlled evaluation. Journal of Social Work Education, 40(1), 105-119. https://doi. org/10.1080/10437797.2004.10778482

Ertel, K. A., Berkman, L. F., \& Buxton, O. M. (2011). Socioeconomic status, occupational characteristics, and sleep duration in African/Caribbean immigrants and US White health care workers. Sleep, 34(4), 509-518. https://doi.org/10.1093/sleep/34.4.509

Fuller-Rowell, T. E., Curtis, D. S., El-Sheikh, M., Duke, A. M., Ryff, C. D., \& Zgierska, A. E. (2017). Racial discrimination mediates race differences in sleep problems: A longitudinal analysis. Cultural Diversity and Ethnic Minority Psychology, 23(2), 165-173. https://doi.org/10.1037/ cdp0000104

Gilin, B., \& Kauffman, S. (2015). Strategies for teaching about trauma to graduate social work students. Journal of Teaching in Social Work, 35(4), 378-396. https://doi.org/10.1080/08841233. 2015.1065945

Grandner, M. A., Patel, N. P., Jean-Louis, G., Jackson, N., Gehrman, P. R., Perlis, M. L., \& Gooneratne, N. S. (2013). Sleep-related behaviors and beliefs associated with race/ethnicity in women. Journal of the National Medical Association, 105(1), 4-16. https://doi.org/10.1016/ S0027-9684(15)30080-8

Grant, L., Kinman, G., \& Alexander, K. (2014). What's all this talk about emotion? Developing emotional intelligence in social work students. Social Work Education, 33(7), 874-889. https:// doi.org/10.1080/02615479.2014.891012

Griffiths, A., Royse, D., Murphy, A., \& Starks, S. (2019). Self-care practice in social work education: A systematic review of interventions. Journal of Social Work Education, 55(1), 102-114. https:// doi.org/10.1080/10437797.2018.1491358

Griffiths, A., Royse, D., \& Walker, R. (2018). Stress among child protective service workers: Selfreported health consequences. Children and Youth Services Review, 90, 46-53. https://doi.org/ 10.1016/j.childyouth.2018.05.011

Hauri, P. J. (1991). Sleep hygiene, relaxation therapy, and cognitive interventions. In P. J. Hauri (Ed.), Case studies in insomnia (pp. 65-84). Springer. https://doi.org/10.1007/978-1-4757-9586-8_5

Ingram, R. (2013). Emotions, social work practice and supervision: An uneasy alliance? Journal of Social Work Practice, 27(1), 5-19. https://doi.org/10.1080/02650533.2012.745842

Jean-Louis, G., Kripke, D. F., Ancoli-Israel, S., Klauber, M. R., \& Sepulveda, R. S. (2000). Sleep duration, illumination, and activity patterns in a population sample: Effects of gender and ethnicity. Biological Psychiatry, 47(10), 921-927. https://doi.org/10.1016/S0006-3223(99)00169-9 
Kemper, K. J., Mo, X., \& Khayat, R. (2015). Are mindfulness and self-compassion associated with sleep and resilience in health professionals? The Journal of Alternative and Complementary Medicine, 21(8), 496-503. https://doi.org/10.1089/acm.2014.0281

Kim, H., Ji, J., \& Kao, D. (2011). Burnout and physical health among social workers: A three-year longitudinal study. Social Work, 56(3), 258-268. https://doi.org/10.1093/sw/56.3.258

Lee, J. J., Gottfried, R., \& Bride, B. E. (2018). Exposure to client trauma, secondary traumatic stress, and the health of clinical social workers: A mediation analysis. Clinical Social Work Journal, 46 (3), 228-235. https://doi.org/10.1007/s10615-017-0638-1

Mastin, D. F., Bryson, J., \& Corwyn, R. (2006). Assessment of sleep hygiene using the sleep hygiene index. Journal of Behavioral Medicine, 29(3), 223-227. https://doi.org/10.1007/s10865-0069047-6

Menon, B., Karishma, H., \& Mamatha, I. (2015). Sleep quality and health complaints among nursing students. Annals of Indian Academy of Neurology, 18(3), 363. https://doi.org/10.4103/ 0972-2327.157252

Moore, S. E., Bledsoe, L. K., Perry, A. R., \& Robinson, M. A. (2011). Social work students and self-care: A model assignment for teaching. Journal of Social Work Education, 47(3), 545-553. https://doi.org/10.5175/JSWE.2011.201000004

Myers, S. B., Sweeney, A. C., Popick, V., Wesley, K., Bordfeld, A., \& Fingerhut, R. (2012). Self-care practices and perceived stress levels among psychology graduate students. Training and Education in Professional Psychology, 6(1), 55-66. https://doi.org/10.1037/a0026534

Newell, J. M., \& Nelson-Gardell, D. (2014). A competency-based approach to teaching professional self-care: An ethical consideration for social work educators. Journal of Social Work Education, 50(3), 427-439. https://doi.org/10.1080/10437797.2014.917928

O’Neill, M., Yoder Slater, G., \& Batt, D. (2019). Social work student self-care and academic stress. Journal of Social Work Education, 55(1), 141-152. https://doi.org/10.1080/10437797.2018. 1491359

Pallos, H., Gergely, V., Yamada, N., Miyazaki, S., \& Okawa, M. (2007). The quality of sleep and factors associated with poor sleep in Japanese graduate students. Sleep and Biological Rhythms, 5 (4), 234-238. https://doi.org/10.1111/j.1479-8425.2007.00316.x

Pilcher, J. J., Band, D., Odle-Dusseau, H. N., \& Muth, E. R. (2007). Human performance under sustained operations and acute sleep deprivation conditions: Toward a model of controlled attention. Aviation, Space, and Environmental Medicine, 78(5 Suppl), B15-B24. https://www. ingentaconnect.com/content/asma/asem

Pilcher, J. J., Ginter, D. R., \& Sadowsky, B. (1997). Sleep quality versus sleep quantity: Relationships between sleep and measures of health, well-being and sleepiness in college students. Journal of Psychosomatic Research, 42(6), 583-596. https://doi.org/10.1016/S0022-3999(97)00004-4

Rauktis, M. E., \& Thomas, T. L. (2013). Reflective practices in supervision: Why thinking and reflecting are as important as doing. In H. Cahalane (Ed.), Contemporary issues in child welfare practice. Contemporary social work practice (pp. 235-256). Springer.

Roberts, R. E., Roberts, C. R., \& Duong, H. T. (2009). Sleepless in adolescence: Prospective data on sleep deprivation, health and functioning. Journal of Adolescence, 32(5), 1045-1057. https://doi. org/10.1016/j.adolescence.2009.03.007

Rompf, E. L., \& Royse, D. (1994). Choice of social work as a career: Possible influences. Journal of Social Work Education, 30(2), 163-171. https://doi.org/10.1080/10437797.1994.10672227

Ruiter, M. E., DeCoster, J., Jacobs, L., \& Lichstein, K. L. (2011). Normal sleep in African-Americans and Caucasian-Americans: A meta-analysis. Sleep Medicine, 12(3), 209-214. https://doi.org/10.1016/j. sleep. 2010.12 .010

Salloum, A., Kondrat, D. C., Johnco, C., \& Olson, K. R. (2015). The role of self-care on compassion satisfaction, burnout and secondary trauma among child welfare workers. Children and Youth Services Review, 49, 54-61. https://doi.org/10.1016/j.childyouth.2014.12.023

Sato, T., \& Ambo, H. (2018). 0382 Effects of a sleep hygiene and relaxation training program on sleep difficulties: A preliminary analysis of a randomized control study on university students with nighttime sleep problems after the Great East Japan Earthquake of March 2011. Sleep, 41 (suppl_1), A146-A146. https://doi.org/10.1093/sleep/zsy061.381 
Schnurr, P. P., Spiro, A., Vielhauer, M. J., Findler, M. N., \& Hamblen, J. L. (2002). Trauma in the lives of older men: Findings from the normative aging study. Journal of Clinical Geropsychology, 8(3), 175-187. https://doi.org/10.1023/A:1015992110544

Schnurr, P., Vielhauer, M., Weathers, F., \& Findler, M. (1999). Brief Trauma Questionnaire. White River Junction, VT: National Center for PTSD. https://doi.org/10.1037/t07488-000

Shannon, P. J., Simmelink-McCleary, J., Im, H., Becher, E., \& Crook-Lyon, R. E. (2014). Developing self-care practices in a trauma treatment course. Journal of Social Work Education, 50(3), 440-453. https://doi.org/10.1080/10437797.2014.917932

Sivertsen, B., Bøe, T., Skogen, J. C., Petrie, K. J., \& Hysing, M. (2017). Moving into poverty during childhood is associated with later sleep problems. Sleep Medicine, 37, 54-59. https://doi.org/10. 1016/j.sleep.2017.06.005

Smart, K. (2019). Investigating the effects of sleep hygiene education on sleep behaviors and academic performance in community college students. Sleep Medicine, 64, S355-S356. https:// doi.org/10.1016/j.sleep.2019.11.992

Spadola, C., Groton, D., Lopez, R., Burke, S. L., Hilditch, C. J., Pandey, A., Littlewood, K., Zhou, E. S., \& Bertisch, S. M. (2020). 1168 Preliminary impact of a sleep health educational module for social work students. Sleep, 43(Supplement_1), A446-A446. https://doi.org/10. 1093/sleep/zsaa056.1162

Stepanski, E. J., \& Wyatt, J. K. (2003). Use of sleep hygiene in the treatment of insomnia. Sleep Medicine Reviews, 7(3), 215-225. https://doi.org/10.1053/smrv.2001.0246

Thomas, J. T. (2016). Adverse childhood experiences among MSW students. Journal of Teaching in Social Work, 36(3), 235-255. https://doi.org/10.1080/08841233.2016.1182609

Watling, J., Pawlik, B., Scott, K., Booth, S., \& Short, M. A. (2017). Sleep loss and affective functioning: More than just mood. Behavioral Sleep Medicine, 15(5), 394-409. https://doi.org/ $10.1080 / 15402002.2016 .1141770$

Whinnery, J., Jackson, N., Rattanaumpawan, P., \& Grandner, M. A. (2014). Short and long sleep duration associated with race/ethnicity, sociodemographics, and socioeconomic position. Sleep, 37(3), 601-611. https://doi.org/10.5665/sleep.3508

Whitaker, T., Reich, S., Reid, L. B., Williams, M., \& Woodside, C. (2004). If you're right for the job; it's the best job in the world: The National Association of Social Workers' child welfare specialty practice section members describe their experiences in child welfare. National Association of Social Workers.

Yoo, S.-S., Gujar, N., Hu, P., Jolesz, F. A., \& Walker, M. P. (2007). The human emotional brain without sleep-A prefrontal amygdala disconnect. Current Biology, 17(20), R877-R878. https:// doi.org/10.1016/j.cub.2007.08.007

Zhang, J., Lau, E. Y. Y., \& Hsiao, J. H. (2019). Sleep deprivation compromises resting-state emotional regulatory processes: An EEG study. Journal of Sleep Research, 28(3), e12671. https://doi.org/10.1111/jsr.12671 